\title{
IL-17 intensifies IFN- $\gamma$-induced NOS2 upregulation in RAW 264.7 cells by further activating STAT1 and NF-кB
}

\author{
QIYUE GAO $^{1 *}$, YANG LIU $^{1 *}$, YAN WU $^{1}$, QIANG ZHAO $^{1}$, LIJUN WANG $^{1,2}$, SHANSHAN GAO $^{1}$, \\ WEN WEN $^{1}$, WEIPING ZHANG ${ }^{1}$, NING GUO ${ }^{1}$, JUAN ZHOU ${ }^{1,2}$ and ZUYI YUAN ${ }^{1-3}$ \\ ${ }^{1}$ Department of Cardiovascular Medicine, ${ }^{2}$ Key Laboratory of Molecular Cardiology, The First Affiliated Hospital of \\ Xi'an Jiaotong University; ${ }^{3}$ Key Laboratory of Environment and Genes Related to Diseases, \\ Xi'an Jiaotong University, Xi'an, Shaanxi 710061, P.R. China
}

Received September 23, 2015; Accepted December 8, 2015

DOI: $10.3892 /$ ijmm.2015.2433

\begin{abstract}
Interleukin-17 (IL-17) is a signature cytokine of Th17 cells. Previous research has indicated that IL-17 plays a proinflammatory role by exacerbating interferon- $\gamma$ (IFN- $\gamma$ )-induced inflammation. However, prior to this study, it was not known whether inducible nitric oxide synthase (iNOS or NOS2), a signature molecule of inflammation, could be intensified by IL-17 when combined with IFN- $\gamma$. Thus, we explored the roles and underlying mechanisms of IL-17 and IFN- $\gamma$ in the regulation of NOS2 expression in RAW 264.7 cells using qPCR, western blot analysis, colorimetric analysis, ChIP assay and statistical analysis. Although IL-17 alone did not induce NOS2 expression or nitric oxide (NO) production, as shown by western blot analysis and colorimetric analysis, it intensified IFN- $\gamma$-induced NOS2 upregulation and NO production in RAW 264.7 cells. The alteration of relevant transcription factors demonstrated that a combination of IFN- $\gamma$ and IL-17 enhanced Tyr701-phosphorylated signal transducer and activator of transcription 1 [p-STAT1(Y701)] and nuclear factor- $\kappa \mathrm{B}(\mathrm{NF}-\mathrm{\kappa B})$ activation, nuclear translocations and their binding to the NOS2 promoter, compared with IFN- $\gamma$ alone, as illustrated by the results of the western blot analysis and ChIP assay. Also, using the corresponding inhibitors of STAT1 and $\mathrm{NF}-\mathrm{\kappa B}$, we noted downregulation of the expression of NOS2 induced by IFN- $\gamma$ alone or in combination with IL-17, respectively. In addition, IFN- $\gamma$ increased phosphorylated (p-)p38 mitogen-activated protein kinase (MAPK), and accelerated the
\end{abstract}

Correspondence to: Professor Juan Zhou or Professor Zuyi Yuan, Department of Cardiovascular Medicine, The First Affiliated Hospital of Xi'an Jiaotong University, 277 West Yanta Road, Xi'an, Shaanxi 710061, P.R. China

E-mail: 1306899042@qq.com

E-mail: zuyiyuan@mail.xjtu.edu.cn

*Contributed equally

Key words: interleukin-17, interferon- $\gamma$, inducible nitric oxide synthase, nuclear factor- $\kappa \mathrm{B}$, signal transducer and activator of transcription 1, p38 mitogen-activated protein kinase, extracellular signal-regulated kinase $1 / 2$ activation of the NF- $\mathrm{kB}$ pathway and the expression of NOS2, but phosphorylated extracellular signal-regulated kinase $1 / 2$ (p-ERK1/2) was reduced by treatment with IFN- $\gamma$ and IL-17. IL-17 intensified the activation of the NF- $\mathrm{KB}$ pathway and NOS2 upregulation induced by IFN- $\gamma$ by increasing the phosphorylation of p38 MAPK and limiting the phosphorylation of ERK1/2. Taken together, these results suggest that IL-17 intensified IFN- $\gamma$-induced NOS2 upregulation and NO production by increasing the transcription activity of p-STAT1(Y701) and NF- $\kappa$ B in RAW 264.7 cells. Further activation of the NF- $\kappa B$ pathway induced by IL-17 relied on enhanced phosphorylation of p38 MAPK and decreased phosphorylation of ERK1/2. The mechanism suggested in this study provides novel information which may be used for anti-inflammatory therapy with IL-17.

\section{Introduction}

Inducible nitric oxide synthase (iNOS or NOS2) expression can be induced by a variety of inflammatory cytokines (1). NOS2 exerts its functions by catalyzing L-arginine to nitric oxide (NO), resulting in large amounts of free radicals (2). The primary function of NOS2 is macrophage-mediated non-specific immune defense against intracellular bacteria (3) and certain tumor cells (4). In pathophysiological cases, uncontrolled NOS2 released at the wrong sites has been associated with allograft rejection (5), neurodegeneration (6) and septic shock (7).

As a signature cytokine of M1 macrophages, interferon- $\gamma$ (IFN- $\gamma$ ) plays a key role in activation, inflammation and host defense against the intracellular pathogens of macrophages (8). Moreover, IFN- $\gamma$ is also an inducer of NOS2, and promotes NOS2 expression by activating several related transcription factors, such as nuclear factor- $\mathrm{kB}(\mathrm{NF}-\mathrm{\kappa B})$ and signal transducer and activator of transcription 1 (STAT1) and causing them to bind to the NOS2 promoter $(9,10)$.

Interleukin-17 (IL-17) is a signature cytokine of Th17 cells (11). Aberrant production of IL-17 is associated with autoimmune and inflammatory diseases: for example, delayed onset, reduced maximum severity scores, and early recovery have been observed in IL-17-deficient mice in a model of experimental autoimmune encephalomyelitis (EAE) (12). Previously it was noted that blockade of IL-17 in ApoE-deficient mice induces impaired monocyte/macrophage recruitment to the aortic wall, 
leading to reduced atherosclerosis (13). It has been reported that IL-17 facilitates the expression of inflammatory chemokines and cytokines through the $\mathrm{NF}-\kappa \mathrm{B}, \mathrm{p} 38$ mitogen-activated protein kinase (MAPK) and extracellular signal-regulated kinase (ERK) pathways $(14,15)$. These secreted factors are known to be responsible for the recruitment of monocytes and lymphocytes, which eventually aggravate inflammation (16). Previous research has also revealed that the inflammatory effect of IL-17 is partially related to the synergistic effects it exerts with other cytokines, including tumor necrosis factor- $\alpha$ (TNF- $\alpha$ ) (17).

Increased IFN- $\gamma$ has been noted in a mouse model of atherosclerosis, where IL-17 plays a proinflammatory role (18). Moreover, it has also been noted that IL-17 synergistically acts with IFN- $\gamma$ to induce an inflammatory response in vascular smooth muscle cells by enhancing the expression of inflammatory cytokines and chemokines (19). In the present study, we aimed to investigate whether synergistic effects between IL-17 and IFN- $\gamma$ in the inflammatory response could be noted in macrophages, especially in relation to NOS2 expression.

\section{Materials and methods}

Reagents. The recombinant murine IFN- $\gamma$ and IL-17 were purchased from PeproTech (Rock Hill, NJ, USA). The STAT1 inhibitor fludarabine (Flu), JAK inhibitor AG-490, NF- $\mathrm{B}$ inhibitor SN50, phosphorylated (p-)p38 inhibitor SB203580, p-ERK1/2 inhibitor PD98059 and also antibody against p-p38 MAPK(Thr180/Tyr182) (sc-17852-R) were all supplied by Santa Cruz Biotechnology, Inc. (Shanghai, China). The antibodies against NOS(pan) (\#2977), p-STAT1(Y701) (\#7649), p-STAT1(S727) (\#8826), p-ERK1/2(Thr202/Tyr204) (\#4370) and p65 (\#8242) were all purchased from Cell Signaling Technology (Danvers, MA, USA). Antibody against STAT1 (\#21044-1) was supplied by Signalway Antibody (Baltimore, MD, USA). Antibodies against $\beta$-actin (20536-1-AP) and histone H3 (17168-1-AP) were obtained from Proteintech

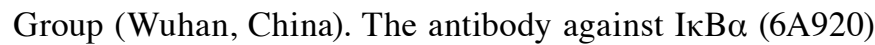
was purchased from Novus Biologicals (Littleton, CO, USA). Horseradish peroxidase-conjugated goat anti-rabbit (A21020) and goat anti-mouse (A21010) secondary antibodies were both obtained from Abbkine (Redlands, CA, USA).

Cell culture. A murine macrophage cell line (RAW 264.7) was obtained from the American Type Culture Collection (Manassas, VA, USA) and maintained in Dulbecco's modified Eagle's medium (DMEM) supplemented with $10 \%$ fetal bovine serum (both from Life Technologies, Carlsbad, CA, USA). Cells were incubated in serum-free medium overnight before treatment. In order to explore the roles of the signaling factors involved, cells were pretreated with the previously mentioned specific inhibitors for specified periods of time prior to cytokine exposure.

Animal and treatment protocol. All animal procedures were approved by the Institutional Ethics Committee for Animal Experiments of Xi'an Jiaotong University. All surgical and experimental procedures were carried out in accordance with the National Institutes of Health Guide for the Care and Use of Laboratory Animals (NIH publications number 23-80) revised in 2011. Animal maintenance was in accordance with
The National Institutes of Health guidelines on care and use of animal subjects in research (National Academy of Science, 1996). All mice had readily access to normal chow and were housed collectively on a $12 \mathrm{~h}$ light-dark cycle (lights on from 8:00 a.m. to 8:00 p.m.) in a facility accredited by the Association for the Assessment and Accreditation of Laboratory Animal Care. All experiments were carried out using 6 to 8-week-old C57BL/6J mice purchased from the Center of Laboratory Animal Science of Xi'an Jiaotong University (Shaanxi, China) weighing 20-30 g. Four mice were intraperitoneally injected with Brewer thioglycollate medium 48 h before being sacrificed by cervical dislocation. The peritoneal macrophages were acquired by intraperitoneal lavage of the sacrificed mice with DMEM on a clean bench.

NO detection in medium. RAW 264.7 cells were stimulated with cytokines for 24 or $48 \mathrm{~h}$. Nitrite concentration, a measure of NO production, was determined by Griess reaction using a QuantiChrom $^{\mathrm{TM}}$ Nitric Oxide Assay kit (BioAssay Systems, Hayward, CA, USA). Briefly, $100 \mu \mathrm{l}$ supernatant was mixed with an equal volume of Griess reagent (1\% sulfanilamide, $5 \%$ phosphoric acid and $0.1 \% \mathrm{~N}-(1-n a p h t h y l)-e t h y l e n e d i a m i n e)$, and the mixture was incubated at room temperature for $10 \mathrm{~min}$. Absorbance was measured at a wavelength of $540 \mathrm{~nm}$ using a microplate reader (Molecular Devices Corporation, Sunnyvale, CA, USA). Nitrite concentration was then calculated from a $\mathrm{NaNO}_{2}$ standard curve.

Quantitative PCR ( $q P C R$ ). Total RNA was extracted from cells using TRIzol reagent (Invitrogen, Carlsbad, CA, USA) according to the manufacturer's instructions. First-strand cDNA was synthesized using the RevertAid ${ }^{\mathrm{TM}}$ First Strand cDNA Synthesis kit (Fermentas, Vilnius, Lithuania). qPCR was performed on the IQ5 ${ }^{\mathrm{TM}}$ Multicolor real-time PCR Detection System (Bio-Rad, Hercules, CA, USA) using SYBR ${ }^{\circledR}$ Select Master Mix (Life Technologies). In addition, $\beta$-actin was selected as the housekeeping gene. The primer sequences are summarized in Table I.

Western blot analysis. Whole cell extracts from treated RAW 264.7 cells or peritoneal macrophages were prepared using RIPA buffer (Cybrdi Inc., Gaithersburg, MD, USA) supplemented with $1 \%$ Halt Protease and Phosphatase Inhibitor Cocktail (Thermo Fisher Scientific, Inc., Waltham, MA, USA) according to the manufacturer's instructions. Cytoplasmic and nuclear extracts from treated RAW 264.7 cells were prepared using NE-PER Nuclear and Cytoplasmic Extraction Reagents (Thermo Fisher Scientific, Inc.) supplemented with 1\% Halt Protease and Phosphatase Inhibitor Cocktail (Thermo Fisher Scientific, Inc.) according to the manufacturer's instructions. Protein concentration was determined using a BCA Protein Assay Reagent kit (Thermo Fisher Scientific, Inc.). Proteins were separated by electrophoresis on an SDS-PAGE gel (4-10\%) and then electrotransferred onto a PVDF membrane (Roche Diagnostics, Inc., Indianapolis, IN, USA). Subsequently, the PVDF membrane was incubated with various primary antibodies and then their corresponding secondary antibodies. Immunoreactive bands were visualized using ECL substrate in a ChemiDoc XRS Imaging system (Bio-Rad). In addition, $\beta$-actin and histone $\mathrm{H} 3$ were used as loading controls. 
Table I. Primer sequences used for qPCR.

\begin{tabular}{lllc}
\hline Gene/site & \multicolumn{1}{c}{$\begin{array}{c}\text { Forward primer } \\
\left(5^{\prime} \rightarrow 3^{\prime}\right)\end{array}$} & \multicolumn{1}{c}{$\begin{array}{c}\text { Reverse primer } \\
\left(5^{\prime} \rightarrow 3^{\prime}\right)\end{array}$} & $\begin{array}{c}\text { Product } \\
\text { length (bp) }\end{array}$ \\
\hline $\begin{array}{l}\text { For qPCR (mouse) } \\
\text { NOS2 }\end{array}$ & TGTGGCTACCACATTGAAGA & GCCCCTCACCATTATCTTTAC & 234 \\
$\begin{array}{l}\beta \text {-actin } \\
\text { For ChIP (mouse) }\end{array}$ & CTAAGGCCAACCGTGAAAAG & 104 \\
$\begin{array}{l}\text { Binding sites on NOS2 promoter } \\
\text { GAS (STAT1) }\end{array}$ & ACACGAGGCTGAGCTGACTT & CACACATGGCATGGAATTTT & 151 \\
NF-kB element & CACACAGACTAGGAGTGTCCATCAT & CATAACTGTTCCCAAAGGGAGAGT & 79 \\
$\begin{array}{l}\text { Binding site on GAPDH promoter } \\
\text { RNA polymerase II }\end{array}$ & TACTCGCGGCTTTACGGG & TGGAACAGGGAGGAGCAGAGAGCA & 169 \\
\hline $\begin{array}{l}\text { NOS2, nitric oxide synthase 2, inducible; GAS, interferon-gamma-activated site; STAT1, signal transducer and activator of transcription 1; NF-kB, } \\
\text { nuclear factor-kB; GAPDH, glyceraldehyde 3-phosphate dehydrogenase. }\end{array}$ & \\
\hline
\end{tabular}

Chromatin immunoprecipitation (ChIP) assay. In the present study, the ChIP assay was performed using a Pierce ${ }^{\mathrm{TM}}$ Agarose ChIP kit (purchased from Thermo Fisher Scientific, Inc.) according to the manufacturer's instructions. Briefly, cells were cross-linked with $1 \%$ formaldehyde and then pre-cleared with Protein A/G PLUS Agarose (Thermo Fisher Scientific, Inc.). For the immunoprecipitation assay, cell lysates were incubated with antibodies against p-STAT1(Y701) or p65 (Cell Signaling Technology) at $4^{\circ} \mathrm{C}$ overnight. Rabbit IgG was used as a negative control, whereas anti-RNA polymerase II antibody (\#1862243; Thermo Fisher Scientific, Inc.) was employed as a positive control. As loading controls, $10 \%$ total input samples were used. The primer sequences used for ChIP are shown in Table I.

Statistical analysis. Data were analyzed by one-way analysis of variance (one-way ANOVA) with SPSS 18.0 software. All values are expressed as the means \pm SD unless otherwise stated, and a p-value $<0.05$ was considered to indicate a statistically significant difference.

\section{Results}

IL-17 intensifies NOS2 upregulation and NO production induced by IFN- $\gamma$ in macrophages. RAW 264.7 cells expressed undetectable levels of NOS2 without stimulus. In order to determine the optimal dosage, IFN- $\gamma$ at various concentrations $(1,4$, $10,20,30,50$ and $100 \mathrm{ng} / \mathrm{ml}$ ) was used initially in the present study. Fig. 1A and B show that NOS2 expression increased in a dose-dependent manner after IFN- $\gamma$ treatment, and levels reached half maximal expression when exposed to $20 \mathrm{ng} / \mathrm{ml}$ IFN- $\gamma$ for 24 h. IL-17 alone did not induce NOS2 expression at any dosage (Fig. 1B). However, after RAW 264.7 cells were stimulated with a combination of IL-17 (20 and $50 \mathrm{ng} / \mathrm{ml})$ and IFN- $\gamma$, NOS 2 expression was further augmented, as compared with IFN- $\gamma$ alone (Fig. 1C; 1.27- and 1.43-fold). At the mRNA level, NOS2 upregulation was also significantly increased by treatment with IL-17 $(50 \mathrm{ng} / \mathrm{ml})$ in combination with IFN- $\gamma$ (20 $\mathrm{ng} / \mathrm{ml})$ for $12 \mathrm{~h}$ compared with IFN- $\gamma$ alone (1.50-fold), suggesting that IL-17 intensified IFN- $\gamma$-induced NOS2 transcription (Fig. 1D). Based on these findings, we decided to treat cells with $20 \mathrm{ng} / \mathrm{ml}$ IFN- $\gamma$ and $50 \mathrm{ng} / \mathrm{ml} \mathrm{IL-17}$ in the subsequent experiments. We also detected the release of NO, the prime effective product of NOS2, in the supernatant. Fig. 1E shows that IL-17 significantly increased IFN- $\gamma$-induced NO synthesis after treatment for $24 \mathrm{~h}$ (1.39-fold) and $48 \mathrm{~h}$ (1.10-fold). Moreover, IL-17 significantly intensified IFN- $\gamma$-induced NOS2 upregulation in peritoneal macrophages (2.41-fold), proving that the effect was not a phenomenon peculiar to RAW 264.7 cells (Fig. 1F). The following experiments carried out to determine the mechanisms involved used RAW 264.7 cells only.

STAT1 is involved in the effect of IL-17 on intensifying NOS2 upregulation induced by IFN- $\gamma$ in RAW 264.7 cells. As one of the main transcription factors, STAT1 is believed to play a vital role in the expression of the NOS2 gene (20). Therefore, we evaluated STAT1 activation in order to explore the underlying mechanism of IL-17-mediated upregulation of NOS2 induced by IFN- $\gamma$. Previous research has shown that Tyr701-p-STAT1 is pivotal in STAT1-dependent regulation of NOS2 expression (21). Fig. 2A and B illustrate that although $50 \mathrm{ng} / \mathrm{ml} \mathrm{IL}-17$ per se did not induce phosphorylation of STAT1(Y701), it intensified IFN- $\gamma$-induced p-STAT1(Y701) expression as early as $5 \mathrm{~min}$ after treatment (1.29-fold). We employed Flu, which is an effective inhibitor of STAT1, to explore whether the increased NOS2 upregulation caused by IL-17 was through p-STAT1(Y701). It was confirmed that Flu $(50 \mu \mathrm{M})$ significantly inhibited the expression of STAT1 in RAW 264.7 cells (Fig. 2D). Fig. 2E and F show that when STAT1 expression was inhibited by Flu, p-STAT1(Y701) was obviously decreased, and so was NOS2 expression ( 0.58 -fold in IFN- $\gamma /$ IL-17 group). As Janus kinase (JAK) is a direct activator of STAT1, we also used JAK inhibitor AG-490 to evaluate the role of the JAK/STAT1 pathway in NOS2 expression. Fig. $2 \mathrm{G}$ shows that AG-490 markedly inhibited NOS2 expression.

The nuclear translocation of p-STAT1(Y701) and its binding to IFN-gamma-activated sites (GASs) in the NOS2 promoter are necessary for the expression of NOS2 (20). Fig. 3A demonstrates that translocation of p-STAT1(Y701) to the nucleus was significantly increased after IFN- $\gamma$ treatment for $1 \mathrm{~h}$ (2.6-fold). A combination of IFN- $\gamma$ and IL-17 further increased the amount of p-STAT1(Y701) in the nucleus (1.21-fold vs. IFN- $\gamma$ group). 
A a

NOS2

$\beta$-actin

A b

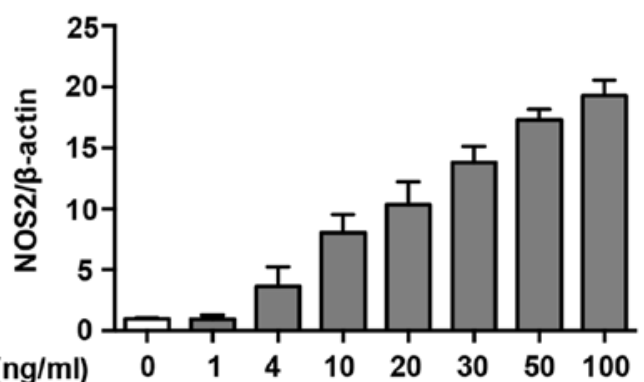

B

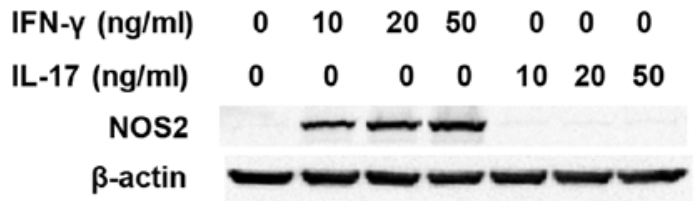

C a

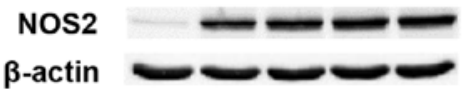

C b

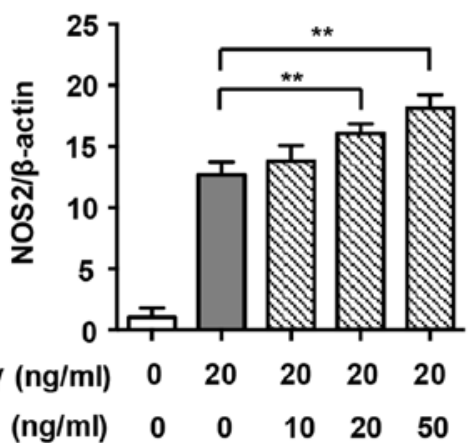

D

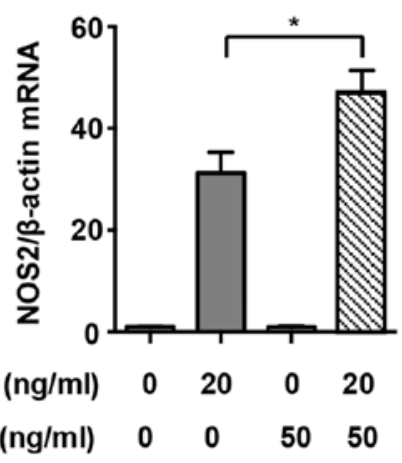

E

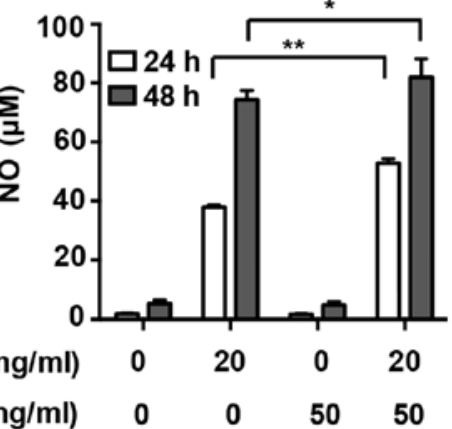

F a

NOS2

$\beta$-actin

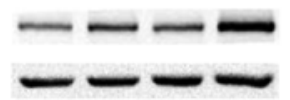

$\mathbf{F} \mathbf{b}$

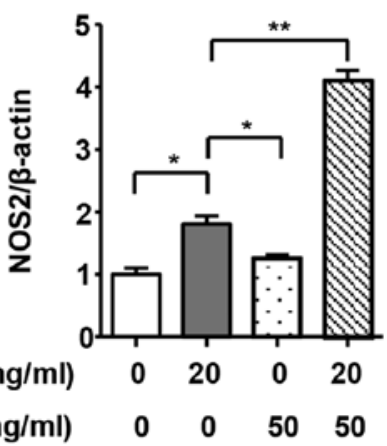

Figure 1. Nitric oxide synthase 2 (NOS2) expression and nitric oxide (NO) production induced by interferon- $\gamma$ (IFN- $\gamma$ ) and/or interleukin-17 (IL-17) in macrophages. (A-a, B and C-a) Representative western blot analysis of NOS2 in RAW 264.7 cells treated with indicated cytokines for 24 h. (A-b and C-b) Average quantification obtained by densitometric analysis for western blot analysis. Data are expressed as the density ratio of target protein to its non-treated level in arbitrary units. (D) Expression of NOS2 at the mRNA level in RAW 264.7 cells treated with indicated cytokines for $12 \mathrm{~h}$. $\beta$-actin was selected as a housekeeping gene. (E) Nitrite concentration in the supernatant of cultured RAW 264.7 cells treated with indicated cytokines for 24 or $48 \mathrm{~h}$. (F-a) Representative western blot analysis and (F-b) quantification of NOS2 in peritoneal macrophages treated with indicated cytokines for $24 \mathrm{~h}$. $\beta$-actin was used as a loading control. Data are presented as the means \pm SD from three independent experiments. ${ }^{*} \mathrm{p}<0.05$ and ${ }^{* *} \mathrm{p}<0.01$.

Proximal GAS in the NOS2 promoter was targeted for amplification in a ChIP assay, as previously described (9). Fig. 3B shows that the binding of p-STAT1(Y701) to GAS was markedly increased after IFN- $\gamma$ treatment for $1 \mathrm{~h}$ (2.63-fold). Although IL-17 alone did not induce the binding of p-STAT1(Y701) to GAS, it considerably enhanced IFN- $\gamma$-induced binding (1.29-fold vs. IFN- $\gamma$ group). The results revealed that supernumerary increases in phosphorylation, nuclear translocation and binding to GAS of p-STAT1(Y701) were closely related to the effect of IL-17-mediated upregulation of NOS2 which was induced by IFN- $\gamma$.

$N F-\kappa B$ is also involved in the effect of IL-17 on intensifying the NOS 2 upregulation induced by IFN- $\gamma$ in RAW 264.7 cells. It has previously been demonstrated that NF- $\kappa \mathrm{B}$, which is another prime transcription factor, also modulates NOS2 expression in mouse macrophages (20). Firstly, we detected the expression of $\mathrm{I} \kappa \mathrm{B} \alpha$, which is an intrinsic inhibitor that binds to p65 and 
A a

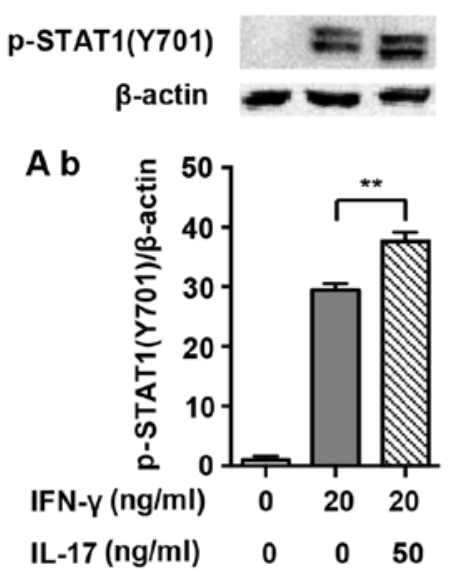

B

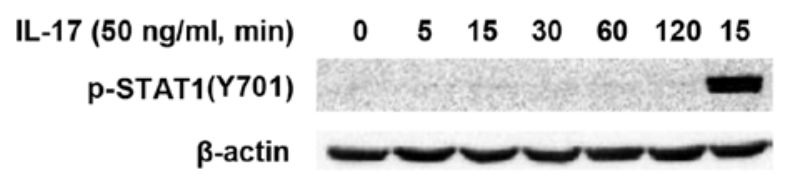

C

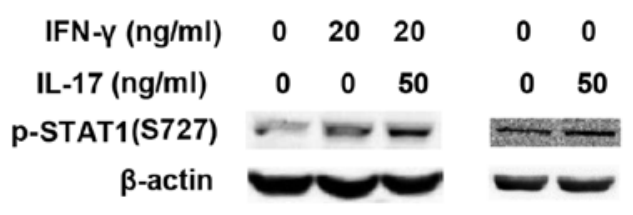

$\mathrm{F} \mathrm{a}$
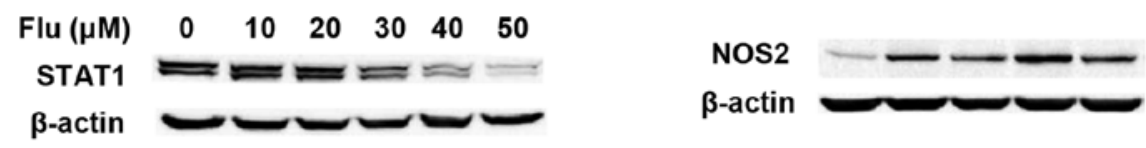

F b

$$
\text { E }
$$

$\begin{array}{rrrrrr}\text { IFN-Y (ng/ml) } & 0 & 20 & 20 & 20 & 20 \\ \text { IL-17 (ng/ml) } & 0 & 0 & 50 & 0 & 50 \\ \text { Flu ( } \mu \mathrm{M}) & 0 & 0 & 0 & 50 & 50 \\ \text { p-STAT1(Y701) } & & =\end{array}$

G

$\begin{array}{ccccccc}\mathrm{IFN}-\mathrm{Y}(\mathrm{ng} / \mathrm{ml}) & 0 & 20 & 20 & 20 & 20 \\ \mathrm{IL}-17(\mathrm{ng} / \mathrm{ml}) & 0 & 0 & 0 & 50 & 50 \\ \mathrm{AG}-490(\mu \mathrm{M}) & 0 & 0 & 20 & 0 & 20 \\ \text { NOS2 } & & & & - & - & -\end{array}$

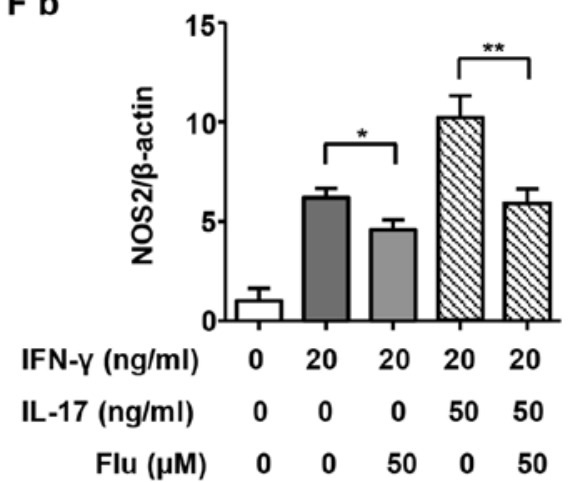

Flu $(\mu \mathrm{M}) \quad 0 \quad 0 \quad 50 \quad 0 \quad 50$

Figure 2. Signal transducer and activator of transcription 1 (STAT1) pathway and nitric oxide synthase 2 (NOS2) expression induced by interferon- $\gamma$ (IFN- $\gamma$ ) and/or interleukin-17 (IL-17) in RAW 264.7 cells. (A-a, B and C) Representative western blot analysis of p-STAT1(Y701) or p-STAT1(S727) in RAW 264.7 cells treated with indicated cytokines for 5 min or specified periods of time. (D) Representative western blot analysis of STAT1 in RAW 264.7 cells treated with STAT1 inhibitor fludarabine (Flu) for 24 h. (E and F-a) Representative western blot analysis of p-STAT1(Y701) or NOS2 in RAW 264.7 cells pretreated with Flu for $24 \mathrm{~h}$ prior to cytokine exposure for 5 min or $24 \mathrm{~h}$. (G) Representative western blot analysis of NOS2 in RAW 264.7 cells pretreated with Janus kinase (JAK) inhibitor AG-490 for 30 min prior to cytokine exposure for 24 h. $\beta$-actin was used as a loading control. (A-b and F-b) Average quantification obtained by densitometric analysis for western blot analysis. Data are expressed as the density ratio of the target protein to its non-treated level in arbitrary units. Data are presented as the means \pm SD from three independent experiments. ${ }^{*} \mathrm{p}<0.05$ and ${ }^{* *} \mathrm{p}<0.01$.

p50 and then degrades after the NF- $\kappa \mathrm{B}$ pathway is activated.

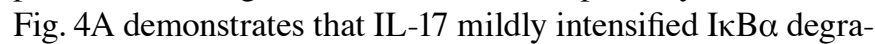
dation (0.89-fold) and, as has also previously been shown, that IL-17 activated the NF- $\kappa \mathrm{B}$ pathway (22). I $\kappa \mathrm{B} \alpha$ degradation was induced by $20 \mathrm{ng} / \mathrm{ml} \mathrm{IFN-} \gamma$ alone (Fig. 4B; 0.74-fold), and it became more significant when treated with a combination of IFN- $\gamma$ and IL-17 (0.65-fold vs. non-treated). SN50, an extrinsic $\mathrm{NF}-\kappa \mathrm{B}$ inhibitor, partially abolished the NOS2 upregulation induced by IFN- $\gamma$ (0.79-fold) or IFN- $\gamma / \mathrm{IL}-17$ (Fig. 4C; 0.62-fold).
We also assessed the nuclear translocation of $\mathrm{NF}-\kappa \mathrm{B}$ and its binding to the NOS2 promoter, and p65 was selected as the representative transcription factor of the NF- $\kappa \mathrm{B}$ pathway. As shown in Fig. 5A, we demonstrated that both IFN- $\gamma$ and IL-17 individually and significantly induced p65 translocation into the nucleus (2.06- and 1.76-fold). However, the combination of IFN- $\gamma$ and IL-17 enhanced p65 translocation into the nucleus (Fig. 5A; 2.50-fold vs. non-treated). The proximal NF- $\kappa \mathrm{B}$ element in the NOS2 promoter was targeted for amplification in a ChIP assay, as has also been previously 
A a

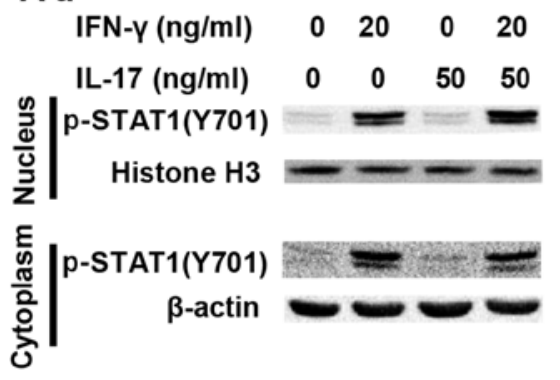

B

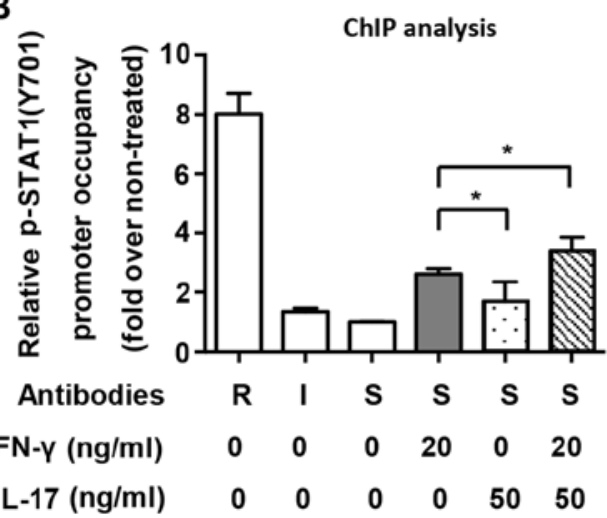

A b
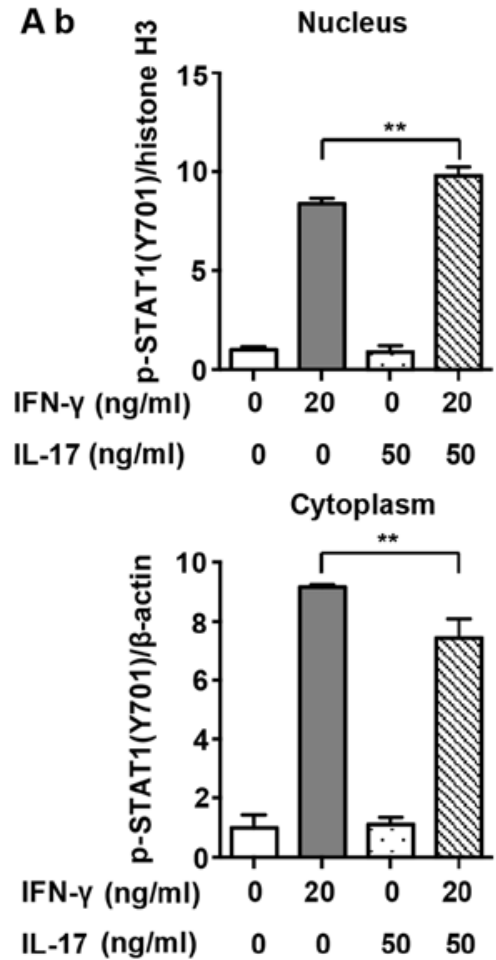

Ac

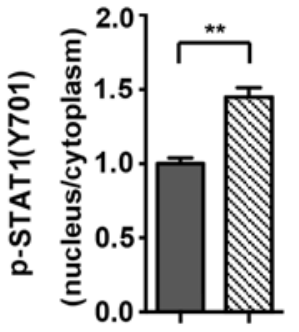

IFN-y (ng/ml) $20 \quad 20$ IL-17 (ng/ml) $\quad 0 \quad 50$

Figure 3. Nuclear translocation and nitric oxide synthase 2 (NOS2) promoter binding of Tyr701-phosphorylated signal transducer and activator of transcription 1 [p-STAT1(Y701)] by interferon- $\gamma$ (IFN- $\gamma$ ) and/or interleukin-17 (IL-17) in RAW 264.7 cells. (A-a) Representative western blot analysis of nuclear translocation of p-STAT1(Y701) in RAW 264.7 cells treated with the indicated cytokines for $1 \mathrm{~h}$. $\beta$-actin was used as a cytoplasmic loading control, and histone $\mathrm{H} 3$ was used as a nuclear loading control. (A-b) Average quantification of nuclear and cytoplasmic p-STAT1(Y701) obtained by densitometric analysis for western blot analysis. Data are expressed as the density ratio of target protein to its non-treated level in arbitrary units. (A-c) p-STAT1(Y701) ratio of nucleus to cytoplasm. (B) Chromatin immunoprecipitation (ChIP) analysis of p-STAT1(Y701) occupancy on the proximal interferon-gamma-activated site (GAS) of NOS2 promoter in RAW 264.7 cells treated with indicated cytokines for $1 \mathrm{~h}$. Antibodies: R, anti-RNA polymerase II antibody; I, IgG; S, anti-p-STAT1(Y701) antibody. Data are presented as the means \pm SD from three independent experiments. ${ }^{*} p<0.05$ and ${ }^{* * *} p<0.01$.

A a

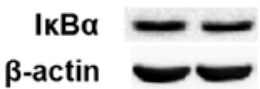

A b

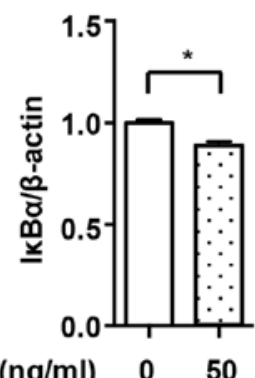

B a

IKBa

$\beta$-actin

B b

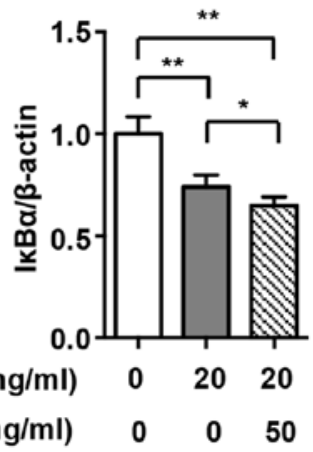

$\mathrm{C}$ a

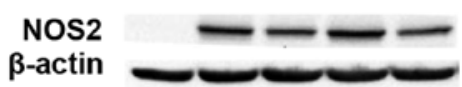

C b

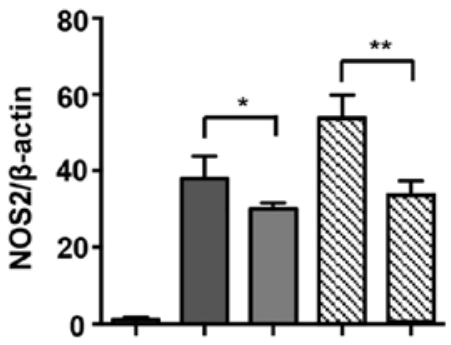

IFN-Y (ng/ml)

020

$\mathrm{IL}-17$ (ng/ml)

$\operatorname{SN50}(\mu \mathrm{M}) \quad 0 \quad 0 \quad 18 \quad 0 \quad 18$

Figure 4. NF- $\kappa B$ pathway and nitric oxide synthase 2 (NOS2) expression induced by interferon- $\gamma$ (IFN- $\gamma$ ) and/or interleukin-17 (IL-17) in RAW 264.7 cells. (A-a and B-a) Representative western blot analysis of IкB $\alpha$ degradation in RAW 264.7 cells treated with the indicated cytokines for $4 \mathrm{~h}$. (C-a) Representative western blot analysis of NOS2 in RAW 264.7 cells pretreated with the NF- $\mathrm{kB}$ inhibitor SN50 for $1 \mathrm{~h}$ prior to cytokine exposure for $24 \mathrm{~h}$. $\beta$-actin was used as a loading control. (A-b, B-b and C-b) Average quantification obtained by densitometric analysis for western blot analysis. Data are expressed as the density ratio of target protein to its non-treated level in arbitrary units. Data are presented as the means \pm SD from three independent experiments. ${ }^{*} p<0.05$ and ${ }^{* *} p<0.01$.

described (9). ChIP analysis demonstrated that IFN- $\gamma$ and IL-17 alone significantly increased the binding of $\mathrm{p} 65$ to the NF- $\mathrm{KB}$ element (1.93- and 1.43-fold); however, we noted that there was no significant difference between these two groups. Compared with treatment with IFN- $\gamma$ or IL-17 individually, the combination of IFN- $\gamma$ and IL-17 further augmented the binding of p65 
A a

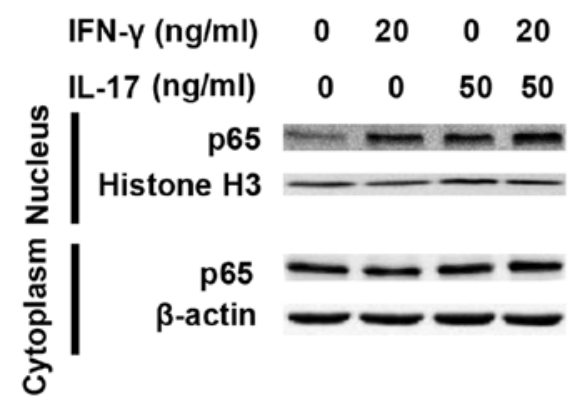

B

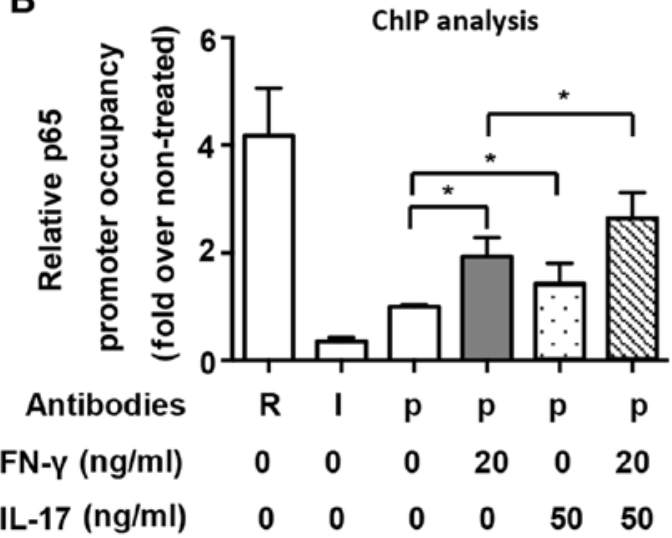

A b

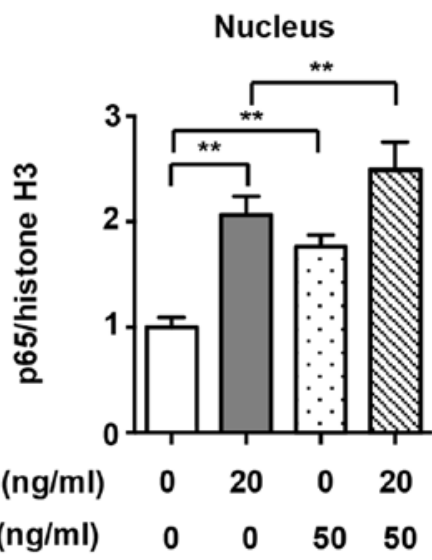

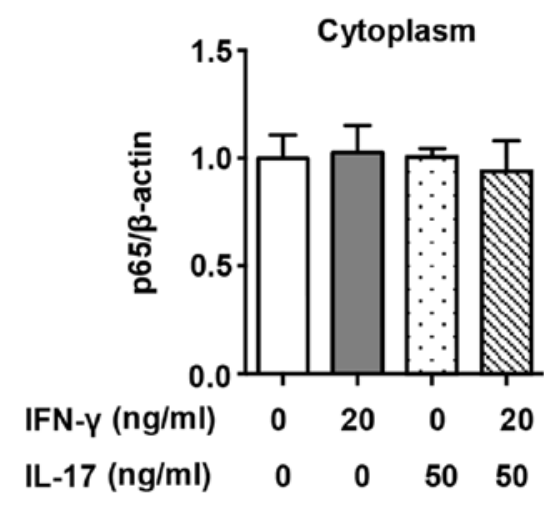

Figure 5. Nuclear translocation and nitric oxide synthase 2 (NOS2) promoter binding of p65 by interferon- $\gamma$ (IFN- $\gamma$ ) and/or interleukin-17 (IL-17) in RAW 264.7 cells. (A-a) Representative western blot analysis of nuclear translocation of p65 in RAW 264.7 cells treated with indicated cytokines for $1 \mathrm{~h}$. $\beta$-actin was used as a cytoplasmic loading control, and histone $\mathrm{H} 3$ was used as a nuclear loading control. (A-b) Average quantification of nuclear and cytoplasmic p65 obtained by densitometric analysis for western blot analysis. Data are expressed as the density ratio of target protein to its non-treated level in arbitrary units. (B) Chromatin immunoprecipitation (ChIP) analysis of p65 occupancy on the proximal NF- $\kappa$ B element of the NOS2 promoter in RAW 264.7 cells treated with indicated cytokines for $1 \mathrm{~h}$. Antibodies: R, anti-RNA Polymerase II antibody; I, IgG; p, anti-p65 antibody. Data are presented as the means \pm SD from three independent experiments. ${ }^{*} \mathrm{p}<0.05$ and ${ }^{* *} \mathrm{p}<0.01$.

to the NF- $\kappa$ B element in RAW 264.7 cells (Fig. 5B; 1.37- and 1.84-fold). These results indicate that IL-17 upregulated NOS2 expression by increasing $\mathrm{I} \kappa \mathrm{B} \alpha$ degradation, enhancing p 65 translocation into the nucleus and accelerating the binding of p65 to the NF- $\kappa \mathrm{B}$ element. Interestingly, we noted that although IL-17 alone activated the $\mathrm{NF}-\kappa \mathrm{B}$ pathway, it did not induce NOS2 expression by itself. This finding suggests that the collaboration between several important transcription factors, including NF- $\mathrm{BB}$ and STAT1, is necessary for NOS2 expression in RAW 264.7 cells.

p-p38 MAPK promotes NOS2 upregulation which is induced by IFN- $\gamma$ alone or in combination with IL-17 in RAW 264.7 cells. We noted that $\mathrm{NF}-\kappa \mathrm{B}$ is modulated by a range of upstream signaling factors, and it has been noted that p38 MAPK is involved in such modulation (23). Thus, we questioned whether p38 MAPK played a role in the IL-17-mediated upregulation of NOS2 induced by IFN- $\gamma$. Fig. 6A shows that both IFN- $\gamma(20 \mathrm{ng} / \mathrm{ml})$ and IL-17 $(50 \mathrm{ng} / \mathrm{ml})$ individually enhanced the phosphorylation of p38 MAPK markedly after 5 min of treatment (1.20- and 1.37-fold). The combination of IFN- $\gamma$ and IL-17 further enhanced the phosphorylation of p38 MAPK as expected (1.58-fold vs. non-treated). Moreover, p-p38 MAPK inhibitor SB203580 considerably inhibited the
NOS2 upregulation induced by IFN- $\gamma$ alone $(0.35$-fold) or that induced by the combination of IFN- $\gamma$ and IL-17 (Fig. 6B; 0.24 -fold). In addition, SB203580 almost completely reversed the I $\kappa \mathrm{B} \alpha$ degradation induced by IFN- $\gamma$ alone (1.23-fold) or in combination with IL-17 (Fig. 6C; 1.45-fold). These data suggest that p-p38 MAPK is an upstream activator of NF- $\kappa B$ and is involved in the regulation of NOS2 expression.

p-ERK1/2 inhibits NOS2 upregulation induced by IFN- $\gamma$ alone or in combination with IL-17 in RAW 264.7 cells. It has previously been demonstrated that ERK1/2 participates in the regulation of the $\mathrm{NF}-\kappa \mathrm{B}$ pathway (23). It has also been noted that IFN- $\gamma$-induced phosphorylation of ERK1/2 increases NOS2 expression in J774A.1 mouse macrophages (24). Therefore, we investigated the roles of ERK1/2 in NOS2 upregulation induced by IFN- $\gamma$ alone or by its combination with IL-17 in RAW 264.7 cells. Although IFN- $\gamma$ and IL-17 alone enhanced the phosphorylation of ERK1/2 after treatment for $30 \mathrm{~min}$ (1.98- and 1.84-fold), the combination of these two cytokines significantly dephosphorylated ERK1/2 almost to its baseline level (Fig. 7A; 0.52- and 0.56-fold). The p-ERK1/2 inhibitor PD98059 markedly enhanced NOS2 expression when cells were exposed to IFN- $\gamma$ alone (Fig. 7B; 1.90 -fold). More importantly, the NOS2 upregulation induced by a combination of 
A a

p-p38

$\beta$-actin

A b

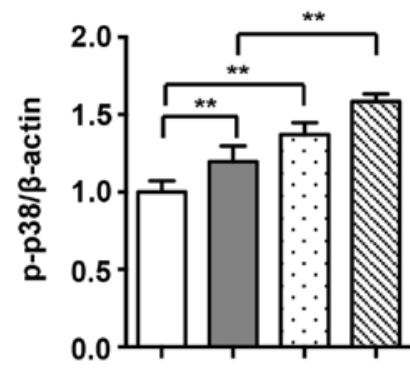

$\begin{array}{lcccc}\text { IFN-Y (ng/ml) } & 0 & 20 & 0 & 20 \\ \text { IL-17 (ng/ml) } & 0 & 0 & 50 & 50\end{array}$

C a

IKB $\alpha$

$\beta$-actin

C b

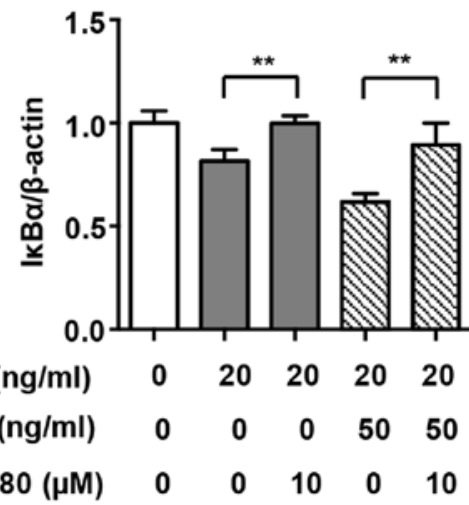

B a

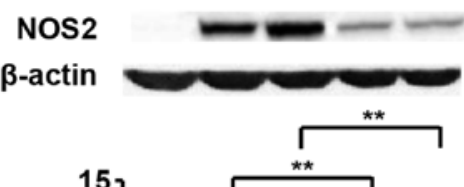

B b

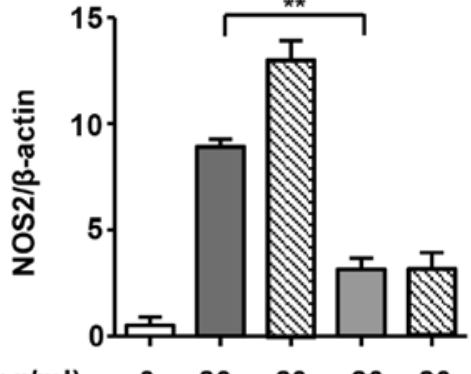

$\begin{array}{cccccc}\text { IFN-Y }(\mathrm{ng} / \mathrm{ml}) & 0 & 20 & 20 & 20 & 20 \\ \text { IL-17 }(\mathrm{ng} / \mathrm{ml}) & 0 & 0 & 50 & 0 & 50 \\ \text { SB203580 }(\mu \mathrm{M}) & 0 & 0 & 0 & 10 & 10\end{array}$

D a

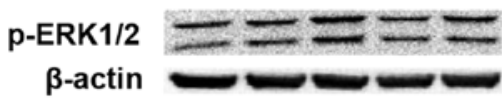

D b

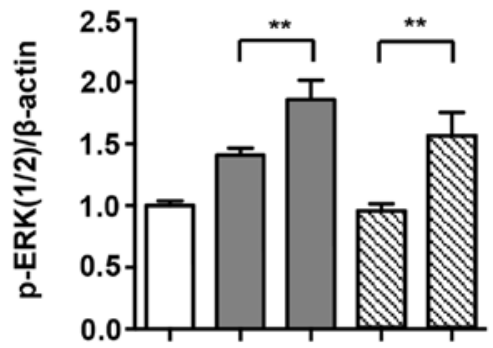

IFN-Y (ng/ml) $\quad \begin{array}{lllll}0 & 20 & 20 & 20 & 20\end{array}$

IL-17 (ng/ml) $\quad 0 \quad 0 \quad 0050 \quad 50$

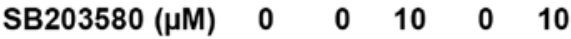

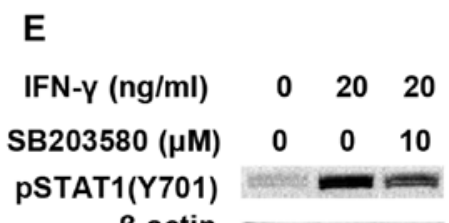

Figure 6. p38 mitogen-activated protein kinase (MAPK) pathway and nitric oxide synthase 2 (NOS2) expression induced by interferon- $\gamma$ (IFN- $\gamma$ ) and/or interleukin-17 (IL-17) in RAW 264.7 cells. (A-a) Representative western blot analysis of p-p38 in RAW 264.7 cells treated with indicated cytokines for 5 min. (B-a and C-a) Representative western blot analysis of NOS2 and I B $\alpha$ degradation in RAW 264.7 cells pretreated with p-p38 inhibitor SB203580 for $30 \mathrm{~min}$ prior to cytokine exposure for 24 or $4 \mathrm{~h}$. (D-a and E) Representative western blot analysis of phosphorylated extracellular signal-regulated kinase $1 / 2$ (p-ERK1/2) or Tyr701-phosphorylated signal transducer and activator of transcription 1 [p-STAT1(Y701)] in RAW 264.7 cells pretreated with SB203580 for 30 min prior to cytokine exposure for 30 or 5 min. $\beta$-actin was used as a loading control. (A-b, B-b, C-b and D-b) Average quantification obtained by densitometric analysis for western blot analysis. Data are expressed as the density ratio of the target protein to its non-treated level in arbitrary units. Data are presented as the means \pm SD from three independent experiments. ${ }^{* *} \mathrm{p}<0.01$.

IFN- $\gamma$ and IL-17 was also enhanced by PD98059 (1.54-fold). Furthermore, PD98059 intensified the I $\kappa \mathrm{B} \alpha$ degradation induced by IFN- $\gamma$ alone $(0.72$-fold) or in combination with IL-17 (Fig. 7C; 0.83-fold). These data indicate that unlike J774A.1 mouse macrophages, IFN- $\gamma$-induced phosphorylation of ERK1/2 plays a negative role in the regulation of NOS2 expression in RAW 264.7 cells. Thus, we suggest that IL-17 alleviates the inhibition of ERK1/2 in cases of IFN- $\gamma$-induced NOS2 upregulation by restricting p-ERK1/2 phosphorylation.

\section{Discussion}

In the present study, we found that although IL-17 alone was unable to induce NOS2 expression, it synergized with IFN- $\gamma$ to amplify NOS2 expression and NO production through the STAT1 and NF- $\mathrm{B}$ pathways in RAW 264.7 cells. The phenomenon of IL-7 on intensifying IFN- $\gamma$-induced NOS2 upregulation does not exist solely in RAW 264.7 cells. It is also found in other macrophages, such as peritoneal macrophages, 
A a

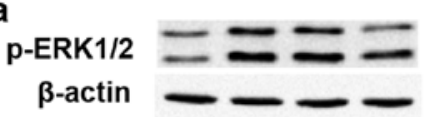

A b

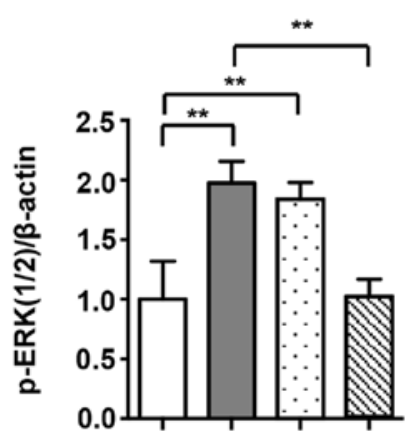

$\begin{array}{lllll}\text { IFN-Y (ng/ml) } & 0 & 20 & 0 & 20 \\ \end{array}$

C a

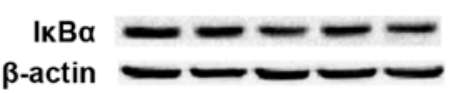

C b

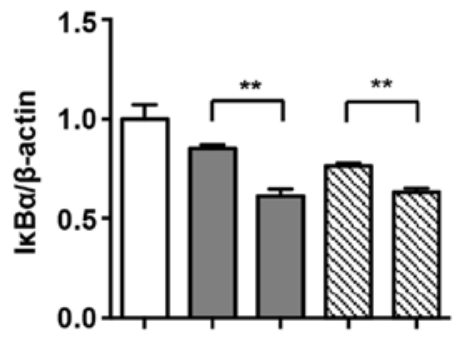

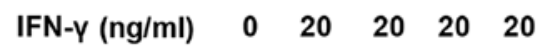

IL-17 (ng/ml) 0000000

$\begin{array}{llllll}\text { PD98059 }(\mu \mathrm{M}) & 0 & 0 & 20 & 0 & 20\end{array}$
B a

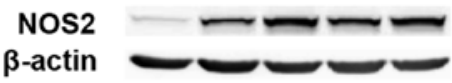

B b

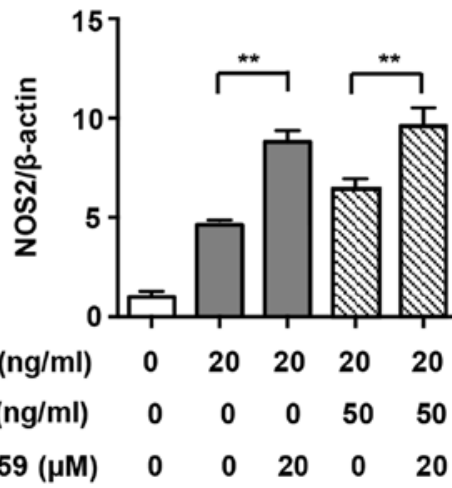

D a

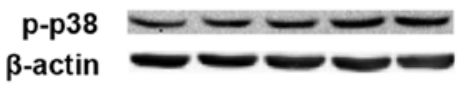

D b

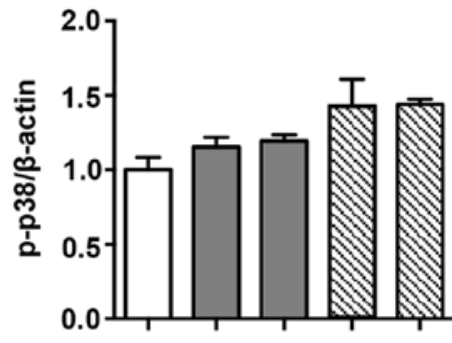

IFN-Y (ng/ml) $\quad \begin{array}{llllll}0 & 20 & 20 & 20 & 20\end{array}$

$\mathrm{IL}-17$ (ng/ml) $\quad 0 \quad 000050$

$\begin{array}{llllll}\text { PD98059 }(\mu \mathrm{M}) & 0 & 0 & 20 & 0 & 20\end{array}$

Figure 7. Extracellular signal-regulated kinase 1/2 (ERK1/2) pathway and nitric oxide synthase 2 (NOS2) expression induced by interferon- $\gamma$ (IFN- $\gamma$ ) and/or interleukin-17 (IL-17) in RAW 264.7 cells. (A-a) Representative western blot analysis of p-ERK1/2 in RAW 264.7 cells treated with indicated cytokines for 30 min. (B-a, C-a and D-a) Representative western blot analysis of NOS2, IкB $\alpha$ degradation and p-p38 in RAW 264.7 cells pretreated with p-ERK1/2 inhibitor PD98059 for $30 \mathrm{~min}$ prior to cytokine exposure for $24 \mathrm{~h}, 4 \mathrm{~h}$ or $5 \mathrm{~min}$. $\beta$-actin was used as a loading control. (A-b, B-b, C-b and D-b) Average quantification obtained by densitometric analysis for western blot analysis. Data are expressed as the density ratio of target protein to its non-treated level in arbitrary units Data are presented as the means \pm SD from three independent experiments. ${ }^{* *} \mathrm{p}<0.01$.

which shows greater significance in exploring the underlying mechanisms.

Macrophages play a key role in inflammation, and NOS2 is a potent inflammatory factor which is regulated by a variety of cytokines. In the present study NOS2 expression and NO production induced by IFN- $\gamma$ were enhanced by IL-17, which intensified host defense reactions, such as the clearance of pathogens. On the other hand, however, the excessive release of NO eventually leads to uncontrolled inflammation and injury of adjacent tissues (25). These data indicate that modulating interaction between different cytokines is a feasible way to acquire the optimal host defense reaction.

As a key molecule of the canonical JAK/STAT1 pathway, p-STAT1(Y701) is phosphorylated by JAK $1 / 2$ and is critical to the upregulation of NOS2 induced by IFN- $\gamma(20,26)$. IL-17 alone did not activate p-STAT1(Y701), but it enhanced the activation, nuclear translocation and binding to the NOS2 promoter of p-STAT1(Y701) induced by IFN- $\gamma$. It has previously been reported that STAT1 is also phosphorylated at Ser727 (27). Dual phosphorylation of STAT1 at Tyr701 and Ser727 is required to induce the full expression of IFN- $\gamma$ activated genes, including NOS2 (27). NOS2 expression is partially inhibited by STAT1(S727A) site mutation (28). We also examined the expression of p-STAT1(S727) induced by IFN- $\gamma$ and IL-17. Fig. $2 \mathrm{C}$ shows that IFN- $\gamma$ and IL-17 alone increased the expression of p-STAT1(S727). The combination of IFN- $\gamma$ and IL-17 further enhanced the phosphorylation of STAT1 at S727 compared with IFN- $\gamma$ alone. However, the exact role of p-STAT1(S727) in the expression of NOS2 induced by IFN- $\gamma$ and IL-17 remains unclear.

$\mathrm{NF}-\kappa \mathrm{B}$ is another important transcription factor in NOS2 expression (20). In the present study, NF- $\kappa \mathrm{B}$ was activated by IFN- $\gamma$ or IL-17 individually. The combination of these two cytokines further activated $\mathrm{NF}-\kappa \mathrm{B}$, which was demonstrated 


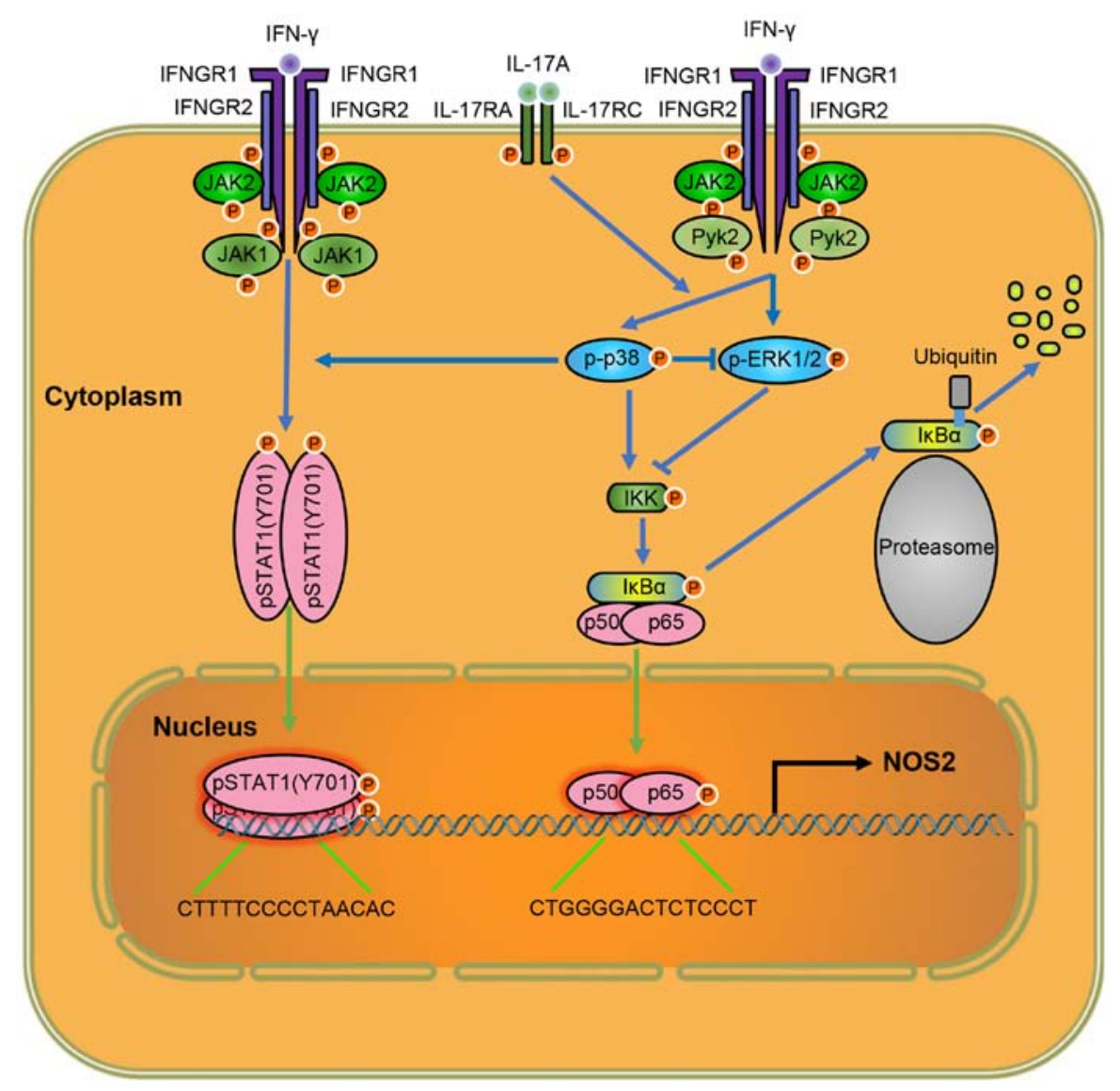

Figure 8. Schematic diagram of the molecular mechanisms by which interleukin-17 (IL-17) intensified interferon- $\gamma$ (IFN- $\gamma$ )-induced nitric oxide synthase 2, inducible (NOS2) upregulation in RAW 264.7 cells. IFNGR1/2, interferon gamma receptor 1/2; p-ERK1/2, phosphorylated extracellular signal-regulated kinase $1 / 2$; JAK1/2, Janus kinase $1 / 2$.

not only by $\mathrm{I} \kappa \mathrm{B} \alpha$ degradation and p 65 translocation into the nucleus, but also the binding of p65 to the NOS2 promoter. The $\mathrm{NF}-\kappa \mathrm{B}$ inhibitor SN50 partially abolished the NOS2 upregulation induced by IFN- $\gamma$ alone or in combination with IL-17. These results demonstrate that IL-17 enhanced IFN- $\gamma$-induced NOS2 upregulation by further activating the NF- $\mathrm{B}$ pathway.

In the present study, IFN- $\gamma$ and IL-17 individually activated p38 MAPK, and in combination they further intensified this activation. Furthermore, the p-p38 MAPK inhibitor SB203580 partially inhibited NOS 2 expression in cells treated with IFN- $\gamma$ alone or in combination with IL-17. Inhibition of p-p38 MAPK by SB203580 reversed the I $\mathrm{B} \alpha \alpha$ degradation induced by IFN- $\gamma$ alone or in combination with IL-17, indicating that I $\mathrm{B} \alpha$ degradation and the activation of $\mathrm{NF}-\kappa \mathrm{B}$ pathway are regulated by p-p38 MAPK. We also noted that SB203580 restrained IFN- $\gamma$-induced phosphorylation of STAT1(Y701) (Fig. 6E). This result suggested that $\mathrm{p} 38$ MAPK was a positive regulator of p-STAT1(Y701), which has been previously reported in dendritic cells (29). As a result, we suggest that the increased phosphorylation of STAT1(Y701) by IL-17 is closely linked with increased p-p38 MAPK activity.

We noted that ERK1/2 played unpredictable and interesting roles in the NOS2 upregulation induced by IFN- $\gamma$ alone or in combination with IL-17 in RAW 264.7 cells. IFN- $\gamma$ and IL-17 individually increased ERK1/2 phosphorylation; however, the combination of these two cytokines markedly decreased ERK1/2 phosphorylation compared with IFN- $\gamma$ alone. Moreover, the $\mathrm{p}-\mathrm{ERK} 1 / 2$ inhibitor PD98059 enhanced I $\mathrm{B} \alpha \alpha$ degradation and increased the NOS2 upregulation induced by IFN- $\gamma$ alone or in combination with IL-17, indicating that $\mathrm{p}$-ERK1/2 plays an inhibitive role in IFN- $\gamma$-induced NOS2 upregulation in RAW 264.7 cells. It has previously been reported that p-ERK1/2 promoted NOS2 expression in murine macrophage cell lines, including J774A.1 (30). The RAW 264.7 cell line was established through intraperitoneal injection of Abelson murine leukemia virus (A-MuLV, an RNA virus) into male $\mathrm{BAB} / 14$ mice and then extracting cells from ascites (31). By contrast, the J774A.1 cell line was established from cells in ascites, which were acquired by percutaneous inoculation of plasmacytoma cells (induced by intraperitoneal injection of saturated hydrocarbons such as Bayol F) into female BALB/c mice (32-34). Therefore, the discrepant functions of $\mathrm{p}-\mathrm{ERK} 1 / 2$ may be explained by the different methods used to acquire these two cell lines. Thus, it is necessary to be cautious when interpreting the role of $\mathrm{p}$-ERK1/2 in the inflammatory response of macrophages.

NOS2 is an inflammatory factor, and its excessive expression induces cell apoptosis (35). We believe that the simultaneous activation of $\mathrm{p} 38$ MAPK and ERK $1 / 2$ induced by IFN- $\gamma$ alone restricts the overexpression of NOS2 and over-production of NO in RAW 264.7 cells, which results in the avoidance of self-damage and possible apoptosis. IL-17 enhanced the NOS 2 upregulation induced by IFN- $\gamma$ by restricting ERK1/2 phosphorylation, in other words, through limiting the inhibitive effect of $\mathrm{p}-\mathrm{ERK} 1 / 2$. 
It has previously been reported that inhibition of the p38 MAPK pathway upregulates ERK1/2 activity in M1 macrophages (36). Our study also demonstrated that inhibition of p38 MAPK facilitated the phosphorylation of ERK1/2 induced by IFN- $\gamma$ (1.21-fold) alone or in combination with IL-17 (Fig. 6D) (1.64-fold). However, inhibition of p-ERK1/2 did not markedly alter p38 MAPK activity (Fig. 7D). These data indicated that $\mathrm{p} 38$ MAPK phosphorylation induced by IFN- $\gamma$ or IFN- $\gamma /$ IL-17 relieved the inhibitive effect of p-ERK1/2 on NOS2 expression in RAW 264.7 cells by restricting its phosphorylation.

Taken together, our results suggest that IL-17 intensifies IFN- $\gamma$-induced NOS2 upregulation and NO production by increasing the transcriptional activity of p-STAT1(Y701) and NF-kB (Fig. 8). Thus, lowering the level of IL-17 is a target for attenuating inflammation, and anti-IL-17 monoclonal antibodies have yielded positive results in inflammatory diseases (37). In addition, considering the roles of p38 MAPK in NOS2 expression, inhibiting the activity of p38 MAPK may also help control excessive inflammation due to tissue injury. As the functions of ERK1/2 on NOS2 expression vary in different macrophages, the cell-type specific regulation of ERK1/2 activity may provide new ideas for the tissue-specific control of inflammation, which may mitigate inflammation and avoid impaired host defense, simultaneously. These important indications provide potential targets for clinical therapies of related diseases. Further exploration of the mechanism of IL-17 on intensifying IFN- $\gamma$-induced NOS2 upregulation may reveal more information on how IL-17 exerts its inflammatory effects, and provide us with more options to regulate inflammation.

\section{Acknowledgements}

This study was supported by the National Natural Science Fund (nos. 91339116, 81170138 and 81200541) and the National Basic Research Program of China ('973 Project' no. 2012CB517804).

\section{References}

1. Rao KM: Molecular mechanisms regulating iNOS expression in various cell types. J Toxicol Environ Health B Crit Rev 3: 27-58, 2000.

2. Aktan F: iNOS-mediated nitric oxide production and its regulation. Life Sci 75: 639-653, 2004.

3. Green SJ, Mellouk S, Hoffman SL, Meltzer MS and Nacy CA: Cellular mechanisms of nonspecific immunity to intracellular infection: cytokine-induced synthesis of toxic nitrogen oxides from L-arginine by macrophages and hepatocytes. Immunol Lett 25: 15-19, 1990.

4. Li LM, Kilbourn RG, Adams J and Fidler IJ: Role of nitric oxide in lysis of tumor cells by cytokine-activated endothelial cells Cancer Res 51: 2531-2535, 1991.

5. Langrehr JM, Hoffman RA, Billiar TR, Lee KK, Schraut WH and Simmons RL: Nitric oxide synthesis in the in vivo allograft response: a possible regulatory mechanism. Surgery 110: 335-342, 1991.

6. Brown GC and Neher JJ: Inflammatory neurodegeneration and mechanisms of microglial killing of neurons. Mol Neurobiol 41: 242-247, 2010

7. Annane D, Sanquer S, Sébille V, Faye A,Djuranovic D, Raphaël JC, Gajdos P and Bellissant E: Compartmentalised inducible nitricoxide synthase activity in septic shock. Lancet 355: 1143-1148, 2000.

8. Zhu J, Yamane H and Paul WE: Differentiation of effector CD4 T cell populations (*). Annu Rev Immunol 28: 445-489, 2010.

9. Goldring CE, Reveneau S, Algarté $M$ and Jeannin JF: In vivo footprinting of the mouse inducible nitric oxide synthase gene: inducible protein occupation of numerous sites including Oct and NF-IL6. Nucleic Acids Res 24: 1682-1687, 1996.
10. Burke SJ, Updegraff BL, Bellich RM, Goff MR, Lu D, Minkin SC Jr, Karlstad MD and Collier JJ: Regulation of iNOS gene transcription by IL- $1 \beta$ and IFN- $\gamma$ requires a coactivator exchange mechanism. Mol Endocrinol 27: 1724-1742, 2013.

11. Gu C, Wu L and Li X: IL-17 family: cytokines, receptors and signaling. Cytokine 64: 477-485, 2013

12. Komiyama Y, Nakae S, Matsuki T, Nambu A, Ishigame H, Kakuta S, Sudo K and Iwakura Y: IL-17 plays an important role in the development of experimental autoimmune encephalomyelitis. J Immunol 177: 566-573, 2006.

13. Smith E, Prasad KM, Butcher M, Dobrian A, Kolls JK, Ley $\mathrm{K}$ and Galkina E: Blockade of interleukin-17A results in reduced atherosclerosis in apolipoprotein E-deficient mice. Circulation 121: 1746-1755, 2010.

14. Laan M, Lötvall J, Chung KF and Lindén A: IL-17-induced cytokine release in human bronchial epithelial cells in vitro: role of mitogen-activated protein (MAP) kinases. Br J Pharmacol 133: 200-206, 2001.

15. Do H, Pyo S and Sohn EH: Suppression of iNOS expression by fucoidan is mediated by regulation of p38 MAPK, JAK/STAT, AP-1 and IRF-1, and depends on upregulation of scavenger receptor B1 expression in TNF-alpha- and IFN-gammastimulated C6 glioma cells. J Nutr Biochem 21: 671-679, 2010.

16. Ouyang W, Kolls JK and Zheng Y: The biological functions of $\mathrm{T}$ helper 17 cell effector cytokines in inflammation. Immunity 28: 454-467, 2008.

17. Griffin GK, Newton G, Tarrio ML, Bu DX, Maganto-Garcia E, Azcutia V, Alcaide P, Grabie N, Luscinskas FW, Croce KJ and Lichtman AH: IL-17 and TNF- $\alpha$ sustain neutrophil recruitment during inflammation through synergistic effects on endothelial activation. J Immunol 188: 6287-6299, 2012.

18. Danzaki K, Matsui Y, Ikesue M, Ohta D, Ito K, Kanayama M, Kurotaki D, Morimoto J, Iwakura Y, Yagita $\mathrm{H}$, et al: Interleukin-17A deficiency accelerates unstable atherosclerotic plaque formation in apolipoprotein E-deficient mice. Arterioscler Thromb Vasc Biol 32: 273-280, 2012.

19. Eid RE, Rao DA, Zhou J, Lo SF, Ranjbaran H, Gallo A, Sokol SI, Pfau S, Pober JS and Tellides G: Interleukin-17 and interferongamma are produced concomitantly by human coronary artery-infiltrating $\mathrm{T}$ cells and act synergistically on vascular smooth muscle cells. Circulation 119: 1424-1432, 2009.

20. Pautz A, Art J, Hahn S, Nowag S, Voss C and Kleinert H: Regulation of the expression of inducible nitric oxide synthase. Nitric Oxide 23: 75-93, 2010.

21. Trinh B, Ko SY, Haria D, Barengo N and Naora H: The homeoprotein DLX4 controls inducible nitric oxide synthase-mediated angiogenesis in ovarian cancer. Mol Cancer 14: 97, 2015.

22. Ruddy MJ, Wong GC, Liu XK, Yamamoto H, Kasayama S, Kirkwood KL and Gaffen SL: Functional cooperation between interleukin-17 and tumor necrosis factor-alpha is mediated by CCAAT/enhancer-binding protein family members. J Biol Chem 279: 2559-2567, 2004.

23. Cargnello $M$ and Roux PP: Activation and function of the MAPKs and their substrates, the MAPK-activated protein kinases. Microbiol Mol Biol Rev 75: 50-83, 2011.

24. Jaramillo M, Naccache PH and Olivier M: Monosodium urate crystals synergize with IFN-gamma to generate macrophage nitric oxide: involvement of extracellular signal-regulated kinase 1/2 and NF-kappa B. J Immunol 172: 5734-5742, 2004.

25. Abramson SB, Amin AR, Clancy RM and Attur M: The role of nitric oxide in tissue destruction. Best Pract Res Clin Rheumatol 15: 831-845, 2001.

26. $\mathrm{Hu} \mathrm{X}$ and Ivashkiv LB: Cross-regulation of signaling pathways by interferon-gamma: implications for immune responses and autoimmune diseases. Immunity 31: 539-550, 2009.

27. van Boxel-Dezaire AH and Stark GR: Cell type-specific signaling in response to interferon-gamma. Curr Top Microbiol Immunol 316: 119-154, 2007.

28. Varinou L, Ramsauer K, Karaghiosoff M, Kolbe T, Pfeffer K, Müller M and Decker T: Phosphorylation of the Stat1 transactivation domain is required for full-fledged IFN-gamma-dependent innate immunity. Immunity 19: 793-802, 2003.

29. Takauji R, Iho S, Takatsuka H, Yamamoto S, Takahashi T, Kitagawa H, Iwasaki H, Iida R, Yokochi T and Matsuki T: CpG-DNA-induced IFN-alpha production involves p38 MAPK-dependent STAT1 phosphorylation in human plasmacytoid dendritic cell precursors. J Leukoc Biol 72: 1011-1019, 2002.

30. Beurel E and Jope RS: Glycogen synthase kinase-3 promotes the synergistic action of interferon-gamma on lipopolysaccharideinduced IL-6 production in RAW264.7 cells. Cell Signal 21: 978-985, 2009. 
31. Raschke WC, Baird S, Ralph P and Nakoinz I: Functional macrophage cell lines transformed by Abelson leukemia virus. Cell 15: 261-267, 1978.

32. Ralph $\mathrm{P}$ and Nakoinz I: Phagocytosis and cytolysis by a macrophage tumour and its cloned cell line. Nature 257: 393-394, 1975.

33. Ralph P, Prichard J and Cohn M: Reticulum cell sarcoma: an effector cell in antibody-dependent cell-mediated immunity. J Immunol 114: 898-905, 1975.

34. Potter M and Lieberman R: Common individual antigenic determinants in five of eight BALB-c IgA myeloma proteins that bind phosphoryl choline. J Exp Med 132: 737-751, 1970.

35. Sharshar T, Gray F, Lorin de la Grandmaison G, Hopkinson NS, Ross E, Dorandeu A, Orlikowski D, Raphael JC, Gajdos P and Annane D: Apoptosis of neurons in cardiovascular autonomic centres triggered by inducible nitric oxide synthase after death from septic shock. Lancet 362: 1799-1805, 2003.
36. Hall JP and Davis RJ: Inhibition of the p38 pathway upregulates macrophage JNK and ERK activities, and the ERK, JNK, and p38 MAP kinase pathways are reprogrammed during differentiation of the murine myeloid M1 cell line. J Cell Biochem 86: $1-11,2002$.

37. Leonardi C, Matheson R, Zachariae C, Cameron G, Li L, Edson-Heredia E, Braun D and Banerjee S: Anti-interleukin-17 monoclonal antibody ixekizumab in chronic plaque psoriasis. $\mathrm{N}$ Engl J Med 366: 1190-1199, 2012. 